\title{
Surgical separation of the uterus and ovaries with simultaneous cannulation of the uterine vein extends luteal function in sheep*
}

\author{
S. E. A. Abdel Rahim $†$, K. P. Bland and N. L. Poyser $\ddagger$ \\ Department of Veterinary Physiology, Royal (Dick) School of Veterinary Studies, University of \\ Edinburgh, Edinburgh EH9 1QH, and $\ddagger$ Department of Pharmacology, University of Edinburgh, \\ Edinburgh EH8 9JZ, U.K.
}

\begin{abstract}
Summary. The insertion of a glass cannula into the uterine branch of the utero-ovarian vein, followed by disconnection of all other tissues between the uterus and the ovary containing the luteal tissue in non-pregnant sheep, was followed by a prolongation of luteal function. A pathway involving uterine venous blood alone is therefore insufficient to explain the transfer of PGF- $2 \alpha$ from the uterus to the ipsilateral ovary. We suggest that lymph is also involved.
\end{abstract}

\section{Introduction}

The vascular integrity between the uterus and ovary is important for the normal control of corpus luteum function in the sheep. Ligation or sectioning of the veins and/or arteries between the uterine horn and the adjacent ovary leads to luteal maintenance (Inskeep \& Butcher, 1966; Kiracofe, Menzies, Gier \& Spiers, 1966; Baird \& Land, 1973; Ginther \& Del Campo, 1973). Barrett et al. (1971) suggested that the uterine luteolytic hormone, prostaglandin (PG) F-2 $\alpha$, might reach the ovary by transfer from the utero-ovarian vein to the ovarian artery by a countercurrent mechanism. Subsequently, McCracken, Baird, Carlson, Goding \& Barcikowski (1973) found evidence that PGF- $2 \alpha$ can pass from the utero-ovarian vein to the ovarian artery by such a mechanism, although the efficiency of the transfer was low (2-10\%). However, the results of Lamond \& Dorst (1973) and Coudert, Phillips, Faiman, Chernecki \& Palmer (1974a, b) do not apparently support the countercurrent hypothesis. These contradictory pieces of evidence indicate that our knowledge of the pathway by which PGF- $2 \alpha$ passes from the uterus to the ovary is incomplete. The purpose of the present investigation was to examine whether an efferent pathway involving the uterine venous blood alone was sufficient to maintain normal luteal regression.

\section{Materials and Methods}

The 16 mature Dorset Horn $\times$ Finnish Landrace ewes used in this investigation were allocated to two groups; a cannulated group and a control group each of 8 animals. Anaesthesia was induced with intravenous injection of $20 \mathrm{ml}$ alphaxalone and alphadolone acetate (Saffan: Glaxo Laboratories Ltd, Greenford, Middlesex) and maintained with nitrous oxide and halothane. All surgery was performed in the first 7 days of the oestrous cycle and all sheep had shown at least 2

* Reprint requests to Dr K. P. Bland.

† Present address: Department of Animal Production, King Saud University, Gassim, Buriydah P.O. Box 1482, Saudi Arabia. 
consecutive oestrous cycles of normal length (16-18 days) before surgery and were not near the end of the breeding season (September-May). Surgery was performed under aseptic conditions via a mid-ventral laparotomy. The ewes selected for cannulation had all ovulated unilaterally, and the uterine vein on the side of the ovary containing the corpus luteum was replaced with a glass cannula. For this replacement the uterine branch of the utero-ovarian vein was first dissected free of connective tissue for 5-10 mm, just anterior to its junction with the ovarian branch. A small longitudinal incision was made into the vein and a siliconized glass cannula (length $20 \mathrm{~mm}$; i.d. $2 \cdot 5$ $\mathrm{mm}$ ) was inserted into the lumen of the vein and anchored in place by two ligatures (Text-fig. 1). The vessel wall overlying the cannula was then cut away and the remaining tissue connections between the uterus and ovary were ligated and severed (Text-fig. 2).
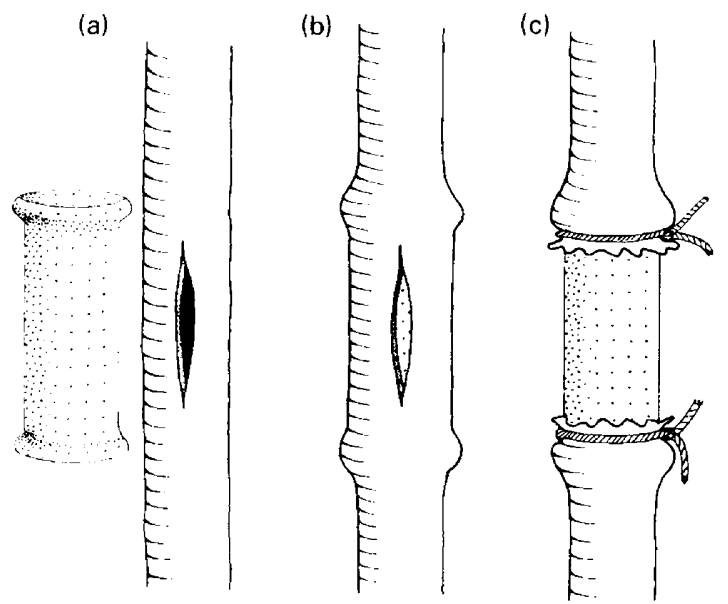

Text-fig. 1. Diagram showing the procedure of replacement of part of the uterine branch of the utero-ovarian vein with a glass cannula. (a) The home-made siliconized glass cannula and the small initial cut made in the vein; (b) the cannula inserted into the lumen of the vein; (c) the cannula ligated in place and the wall of the cannulated part of the vein cut away so that blood passing through the glass cannula was the only connection between the two parts of the vein.

The control ewes were also subjected to laparotomy, and then the uterine vasculature was extensively handled and the main branch of the vein draining the uterus ligated and severed to reduce blood flow down the utero-ovarian vein on the side ipsilateral to the corpus luteum. All other tissues between the uterus and the ovary containing the luteal tissue were left intact including the oviducal vessels.

Daily samples of peripheral blood from the jugular vein were collected from all ewes from the day of surgery onwards. Progesterone concentrations in these blood samples were used to monitor the state of corpora lutea. Plasma progesterone concentrations were measured by radioimmunoassay using a double-antibody technique for separating bound from unbound labelled ligand as developed by Dighe \& Hunter (1974) and described by Poyser \& Horton (1975). The detection limit of the assay was $22 \mathrm{pg} /$ tube. The only significant cross-reactivities were for $11 \alpha-$ hydroxyprogesterone $(37.5 \%), 11 \beta$-hydroxyprogesterone $(29.2 \%)$ and $17 \alpha$-hydroxyprogesterone $(2.0 \%)$; all other substances tested were $\leqslant 0.2 \%$. The intra-assay coefficient of variation was $9.5 \%$ $(n=6)$ while the interassay coefficient of variation was $9.6 \%(n=6)$. Known amounts of progesterone $(0,0 \cdot 5,1,2$ and $4 \mathrm{ng} / \mathrm{ml})$ added to plasma from a ram gave mean recoveries $( \pm$ s.e.m., $n=3$ ) of $0.003 \pm 0.001,0.59 \pm 0 \cdot 10,1.00 \pm 0 \cdot 12,2 \cdot 06 \pm 0.40$ and $4.03 \pm 0.20 \mathrm{ng} / \mathrm{ml}$ respectively.

All animals were killed 18-24 days after the preoperative oestrus to determine the patency of the cannula and the state of the corpus luteum in the ovary on the cannulated side. At post mortem India ink was injected into the uterine vein between the uterus and the cannula and the patency of the cannula observed. 


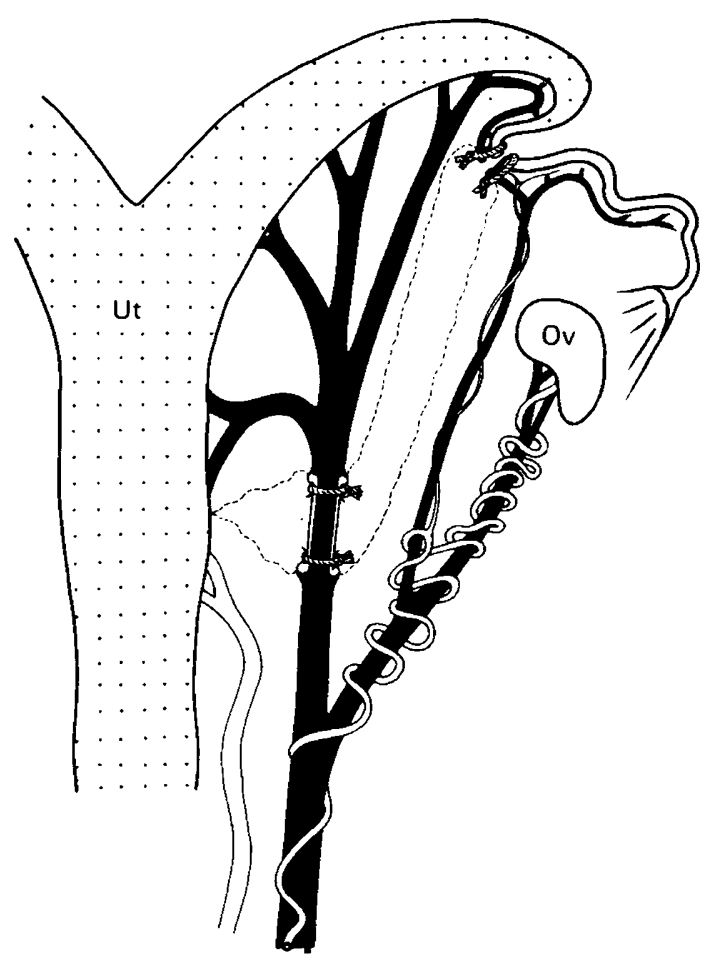

Text-fig. 2. Diagram showing part of the uterine branch of the utero-ovarian vein replaced by a glass cannula. After cannulation of the vein all the remaining connections between the uterine horn and ipsilateral ovary were severed, thus leaving the venous blood passing through the cannulated uterine branch of the vein as the only connection between the uterus and the ovary.

\section{Results}

Examination of the cannulae at autopsy indicated that the cannula was fully patent in 6 of the 8 ewes. In these patent preparations the injection of India ink into the uterine branch of the uteroovarian vein between the uterus and the cannula quickly blackened the veins caudal to the cannula. Table 1 shows the patency of the cannulation and its effect on luteal function. In the 6 ewes with patent cannulae the luteal tissue on the cannulated side had not regressed, yet the vasculature of the ovary and uterus looked normal. Progesterone concentrations in peripheral plasma indicated that

Table 1. The time of operation and autopsy, the patency of the cannulae and state of the corpora lutea in the cannulated ewes

\begin{tabular}{lcccc}
\hline $\begin{array}{c}\text { Sheep } \\
\text { No. }\end{array}$ & $\begin{array}{c}\text { Day of cycle } \\
\text { of surgery }\end{array}$ & $\begin{array}{c}\text { Days from preop. } \\
\text { oestrus to autopsy }\end{array}$ & $\begin{array}{c}\text { Whether cannula } \\
\text { patent }\end{array}$ & $\begin{array}{c}\text { State of CL } \\
\text { at autopsy }\end{array}$ \\
\hline A57 & 4 & 22 & Yes & Maintained \\
A63 & 4 & 22 & Yes & Maintained \\
A17 & 4 & 19 & Yes & Maintained \\
A33 & 5 & 24 & Yes & Maintained \\
A40 & 5 & 18 & No & Fresh* \\
A30 & 7 & 21 & Yes & Maintained \\
A36 & 7 & 20 & No & Maintained \\
A44 & 7 & 21 & Yes & Maintained \\
\hline
\end{tabular}

* This animal returned to oestrus 13 days after surgery, thus showing a normal 18-day cycle. 
all 7 animals not returning to oestrus after operation had maintained luteal tissue that was actively secreting progesterone (Text-fig. 3). However, luteal function in one animal (A40) was unaffected by the surgery in spite of the cannula not being patent and this sheep showed a typical decline in plasma progesterone concentrations before returning to oestrus.

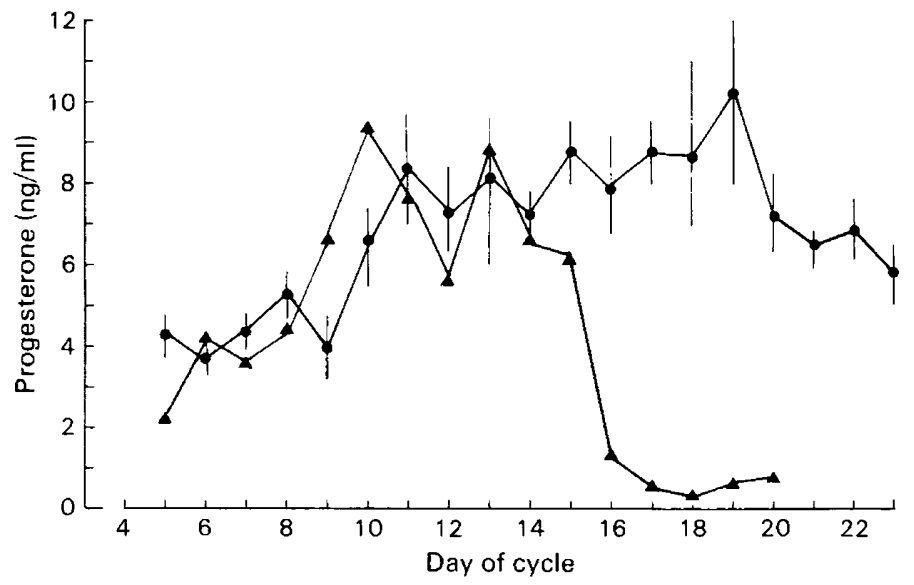

Text-fig. 3. The daily changes of peripheral progesterone concentration (mean \pm s.e.m.) of the 7 ewes that stopped cycling after cannulation of the uterine vein $(O)$ and also those of Ewe A40 (A) that exhibited oestrus after cannulation.

In the control group, 6 of the 8 animals returned to oestrus after an oestrous cycle of normal length, i.e. 16-18 days, while the remaining 2 failed to return to oestrus and progesterone concentrations indicated that their corpora lutea had been maintained in a functional state.

\section{Discussion}

The results of this investigation indicate that luteal function in the ewe was extended when the uterine vein was cannulated and all other direct connections between the uterine horn and the ipsilateral ovary (namely, oviduct and accompanying vessels, broad ligament, nerves, lymphatics and arteries) were surgically separated. Under these conditions the only connection between the uterus and the ipsilateral ovary containing the corpus luteum was the uterine venous blood. Total disconnection of the uterus from the ovary has been shown to delay luteal regression and extend the oestrous cycle (Inskeep \& Butcher, 1966). A similar delay was found in the present experiment even though uterine venous blood was still passing down the utero-ovarian vein and the transfer pathway proposed by McCracken et al. (1973) was still intact. The corpora lutea regressed normally in 6 of the 8 control animals in which blood flow through the utero-ovarian vein had been drastically reduced by severing the main uterine branch of the utero-ovarian vein but leaving all other tissues intact. Thus partial occlusion of the glass cannula reducing uterine venous blood flow through the utero-ovarian vein was unlikely to be the cause of luteal maintenance in the cannulated animals. Ideally the oviducal vessels should also have been severed in the control animals to eliminate the additional pathway for PGF-2 $\alpha$ transport proposed by Alwachi, Bland \& Poyser (1981), but this was not done. Baird \& Land (1973) found that when all the connecting structures between the uterus and ovaries had been severed except the middle uterine vein in ewes, some showed normal regression of the corpus luteum, while others exhibited luteal maintenance. The amount of tissue left around the middle uterine vein in the experiments of Baird \& Land (1973) is unknown, but may have been the deciding factor in whether the corpus luteum regressed or was maintained. The pre- 
sent results indicate that uterine venous blood alone cannot account for a luteolytic factor passing from the uterus to the ipsilateral ovary. The suggestion that lymph may have a physiological role as a transport medium for PGF-2 $\alpha$ (Bland \& Donovan, 1969; Hansel, Concannon \& Lukaszewska, 1973; Kotwica, 1980; Staples, Fleet \& Heap, 1982) now appears probable. Certainly PGF-2 $\alpha$ concentrations in uterine lymph during the oestrous cycle are similar and show similar fluctuations to those in uterine venous blood (Abdel Rahim, Bland \& Poyser, 1983, 1984).

We thank Mr M. Camburn and Mr A. Hussein for assistance with anaesthesia, and the Centre for Laboratory Animals, University of Edinburgh, for animal accommodation and assistance. The work was supported by a grant from the Agricultural Research Council to K.P.B., a Medical Research Council grant to N.L.P. and a Postgraduate Scholarship from the University of Edinburgh to S.E.A.A.R.

\section{References}

Abdel Rahim, S.E.A., Bland, K.P. \& Poyser, N.L. (1983) Prostaglandin $\mathrm{F}_{2 a}$ and $\mathrm{PGE}_{2}$ in uterine lymph during the oestrous cycle in sheep. Prostaglandins, Leuk. \& Med. 10, 157-161.

Abdel Rahim, S.E.A., Bland, K.P. \& Poyser, N.L. (1984) Sequential changes in the concentrations of prostaglandins and steroids in uterine lymph in sheep during the oestrous cycle. Prostaglandins, Leuk. \& Med. (in press).

Alwachi, S.N., Bland, K.P. \& Poyser, N.L. (1981) Additional pathway of transfer of uterine prostaglandin F-2 $\alpha$ to the ovary in sheep. J. Reprod. Fert. 61, 197-200.

Baird, D.T. \& Land, R.B. (1973) Division of the uterine vein and the function of the adjacent ovary in the ewe. J. Reprod. Fert. 33, 393-397.

Barrett, S., Blockley, M.A. de B., Brown, J.M., Cumming, I.A., Goding, J.R., Mole, B.J. \& Obst, J.M. (1971) Initiation of the oestrous cycle in the ewe by infusion of PGF- $2 \alpha$ to the autotransplanted ovary. J. Reprod. Fert. 24, 136-137.

Bland, K.P. \& Donovan, B.T. (1969) Observations on the time of action and the pathway of the uterine luteolytic effect of the guinea-pig. J. Endocr. 43, 259 264.

Coudert, S.P., Phillips, G.D., Faiman, C., Chernecki, W. \& Palmer, M. (1974a) A study of the utero-ovarian circulation in sheep with reference to local transfer between venous and arterial blood. J. Reprod. Fert. 36, 319-331.

Coudert, S.P., Phillips, G.D., Faiman, C., Chernecki, W. \& Palmer, M. (1974b) Infusion of tritiated prostaglandin $F-2 \alpha$ into the anterior uterine vein of the ewe: absence of local venous-arterial transfer. $J$. Reprod. Fert. 36, 333-343.

Dighe, K.K. \& Hunter, W.M. (1974) A solid phase radioimmunoassay for plasma progesterone. Biochem. J. 143, 219-231.
Ginther, O.J. \& Del Campo, C.H. (1973) Vascular anatomy of the uterus and ovaries and the unilateral luteolytic effect of the uterus: area of close apposition between the ovarian artery and vessels which contain uterine venous blood in sheep. Am. J. vet. Res. 34, 1387-1393.

Hansel, W., Concannon, P.W. \& Lukaszewska, J.H. (1973) Corpora lutea of the large domestic animals. Biol. Reprod. 8, 222-245.

Inskeep, E.K. \& Butcher, R.L. (1966) Local component of utero-ovarian relationships in the ewe. J. Anim. Sci. 25, 1164-1168.

Kiracofe, G.H., Menzies, C.S., Gier, H.T. \& Spies, H.G. (1966) Effect of uterine extracts and uterine or ovarian blood vessel ligations on ovarian function of ewes. J. Anim. Sci. 25, 1159-1163.

Kotwica, J. (1980) Mechanism of prostaglandin F-2 $\alpha$ penetration from the horn of the uterus to the ovaries in pigs. $J$. Reprod. Fert. 59, 237-241.

Lamond, D.R. \& Drost, M. (1973) The counter-current transfer of prostaglandin in the ewe. Prostaglandins 3 , 691-695.

McCracken, J.A., Baird, D.T., Carlson, J.C., Goding, J.R. \& Barcikowski, B. (1973) The role of prostaglandins in luteal regression. J. Reprod. Fert., Suppl. 18, $133-142$.

Poyser, N.L. \& Horton, E.W. (1975) Plasma progesterone levels in guinea-pigs actively immunized against prostaglandin $\mathrm{F}_{2 a}$, hysterectomized or treated with intra-uterine indomethacin. $J$. Endocr. 67, 81-88.

Staples, L.D., Fleet, I.R. \& Heap, R.B. (1982) Anatomy of the utero-ovarian lymphatic network and the composition of afferent lymph in relation to the establishment of pregnancy in sheep and goat. $J$. Reprod. Fert. 64, 409-420.

Received 27 February 1984 